\title{
Carbon implications of marginal oils from market-derived demand shocks
}

https://doi.org/10.1038/s41586-021-03932-2

Received: 21 November 2020

Accepted: 18 August 2021

Published online: 3 November 2021

Check for updates

\author{
Mohammad S. Masnadi ${ }^{1 凶}$, Giacomo Benini ${ }^{2}$, Hassan M. El-Houjeiri ${ }^{3}$, Alice Milivinti ${ }^{4}$, \\ James E. Anderson ${ }^{5}$, Timothy J. Wallington ${ }^{5}$, Robert De Kleine ${ }^{5}$, Valerio Dotti ${ }^{6}$, \\ Patrick Jochem ${ }^{7}$ \& Adam R. Brandt ${ }^{2 凶}$
}

\begin{abstract}
Expanded use of novel oil extraction technologies has increased the variability of petroleum resources and diversified the carbon footprint of the global oil supply ${ }^{1}$. Past life-cycle assessment (LCA) studies overlooked upstream emission heterogeneity by assuming that a decline in oil demand will displace average crude oil ${ }^{2}$. We explore the life-cycle greenhouse gas emissions impacts of marginal crude sources, identifying the upstream carbon intensity $(\mathrm{Cl})$ of the producers most sensitive to an oil demand decline (for example, due to a shift to alternative vehicles). We link econometric models of production profitability of 1,933 oilfields ( $-90 \%$ of the 2015 world supply) with their production $\mathrm{Cl}$. Then, we examine their response to a decline in demand under three oil market structures. According to our estimates, small demand shocks have different upstream Cl implications than large shocks. Irrespective of the market structure, small shocks ( $-2.5 \%$ demand) displace mostly heavy crudes with $-25-54 \%$ higher $\mathrm{Cl}$ than that of the global average. However, this imbalance diminishes as the shocks become bigger and if producers with market power coordinate their response to a demand decline. The carbon emissions benefits of reduction in oil demand are systematically dependent on the magnitude of demand drop and the global oil market structure.
\end{abstract}

The energy sector is in a state of rapid change. Several countries announced a variety of 'green' policies to recover from the 2020 COVID19 downturn. Many of these policies could have a long lasting effect on the oil and gas industry ${ }^{3,4}$. The industry could enter into an era of declining demand, technology-led supply response, intense competition, investors' scepticism, and increasing public and government pressure regarding impacts of the oil sector on the environment ${ }^{4}$.

Environmental impacts of oil are commonly measured using LCA methods. The life-cycle carbon footprint, or CI of oil-derived transportation fuels (for example, gasoline) includes the greenhouse gas (GHG) emissions resulting from the combustion of fuels themselves as well as emissions from production and refining of petroleum products. So-called upstream emissions from exploration, extraction and transportation of crude oil differ widely between oilfields $\left(-20-300 \mathrm{~kg} \mathrm{of} \mathrm{CO}_{2}\right.$ equivalent per barrel $\left(\mathrm{kgCO}_{2} \mathrm{e} \mathrm{bbl}^{-1}\right)$ of oil) due to diverse sub-surface geological properties of the deposit, physical and thermodynamic properties of the hydrocarbons, and production and resource management practices ${ }^{1}$. Similarly, 'midstream' emissions from refining vary widely $\left(-10-60 \mathrm{kgCO}_{2} \mathrm{e} \mathrm{bbl}^{-1} \mathrm{oil}\right)$ due to the quality of stream of processed crude and the refining technologies applied ${ }^{5}$. These emissions contribute to variability in the life-cycle $\mathrm{CI}$ of different crude oil supply chains.

The profitability of crude oil production somewhat mirrors the heterogeneity in GHG emissions. The cost-effectiveness of the upstream sector varies due to the properties of the crude extracted, the marginal production costs, the capacity of the producers to affect the global oil price, and the global oil demand elasticity. Thus, some fields are very profitable, while others barely break even.

Recent studies have separately analysed the heterogeneity in the GHG emissions ${ }^{1,5}$ and the economics of the oil market (Benini, G. et al., manuscript in preparation). However, the interaction between the two remains poorly understood. As a result, the characteristics of marginally economic oilfields are not systematically available. This interaction is important because it affects the magnitude of emissions mitigation potential as less profitable oil producers are displaced when demand declines. The demand drops can be due to socio-economic effects (for example, recessions or the ongoing COVID-19 pandemic), substitution effects (for example, more extensive use of alternative fuels/vehicles), and technological change within the transportation sector (for example, greater fuel efficiency).

In the past decade, development of 'consequential' LCA aimed to incorporate numerous economic factors into previously static engineering-based analysis ${ }^{2,6-8}$. These analyses attempt to model income and substitution effects of introducing alternatives, instead of simply assuming that a new product directly displaces an old product. To date, this consequential LCA paradigm has not reached crude oil LCA, and studies of alternatives to crude oil (for example, electric vehicles (EVs)) nearly always assume that an alternative simply displaces average crude oil. The merging of CI and profitability allow us to conduct the first consequential LCA study of the global oil supply (to the best of our knowledge).

The present work connects the upstream CI of 1,933 oilfields ( $90 \%$ of 2015 global crude production) with their profitability. The Cl of fields is

'Department of Chemical and Petroleum Engineering, University of Pittsburgh, Pittsburgh, PA, USA. 'Department of Energy Resources Engineering, Stanford University, Stanford, CA, USA.

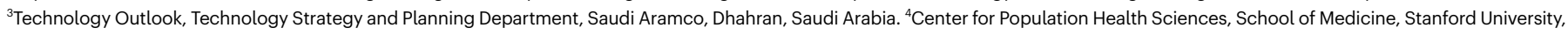
Stanford, CA, USA. ${ }^{5}$ Research and Advanced Engineering, Ford Motor Company, Dearborn, MI, USA. ${ }^{6}$ Department of Economics, Ca' Foscari University of Venice, Venice, Italy. Institute of Networked Energy Systems, German Aerospace Center (DLR), Cologne, Germany. ${ }^{凶}$ e-mail: m.masnadi@pitt.edu; abrandt@stanford.edu 


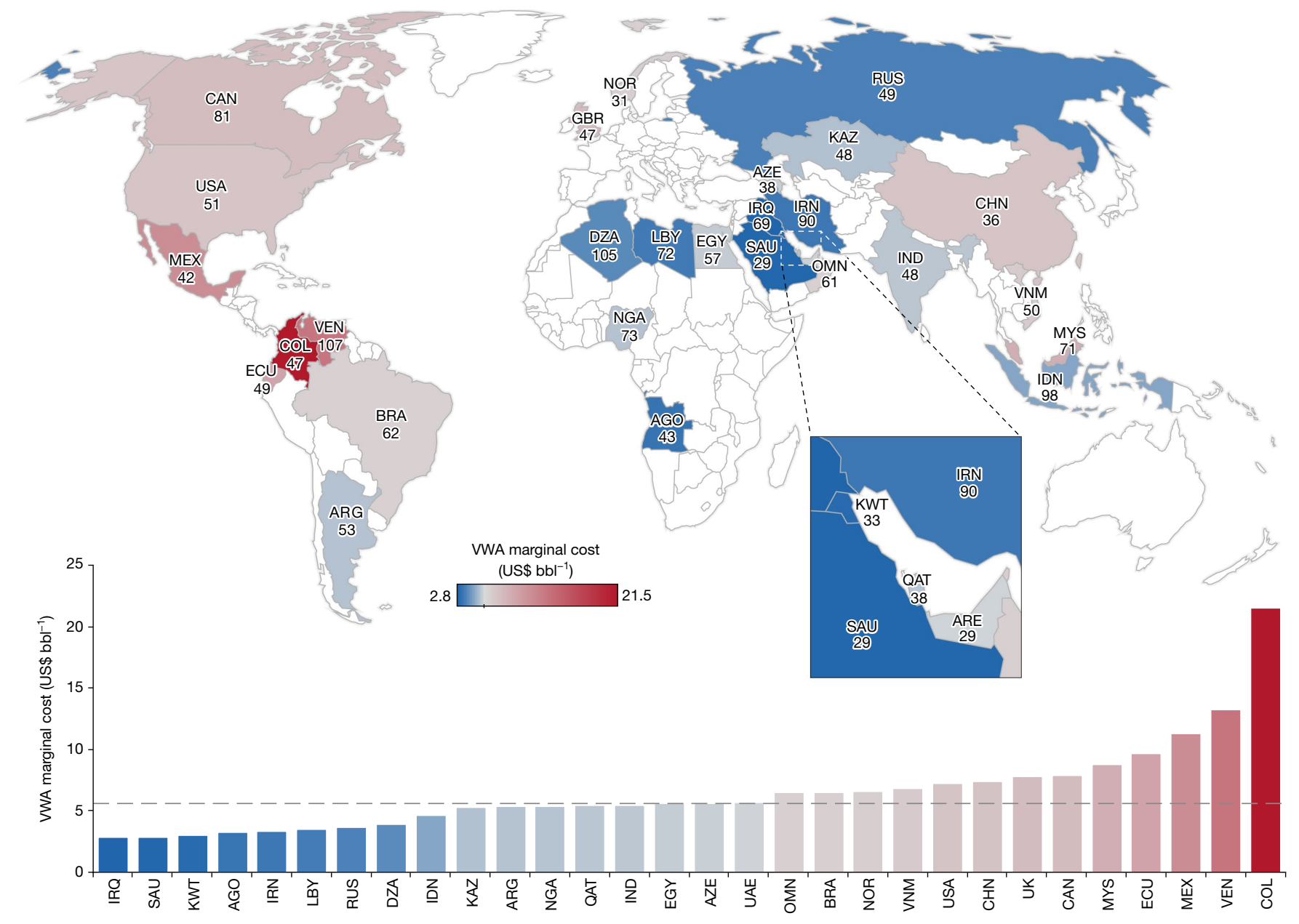

Fig. 1 | Estimated global crude oil upstream marginal cost of production (2015). National volume weighted average (VWA) upstream marginal cost of production in US $\$ \mathrm{bbl}^{-1}$ crude oil produced. Map shows national VWA upstream

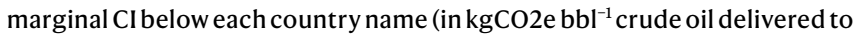
refinery). The global VWA MC estimate is shown by the horizontal dashed line
( US $\left.\$ 5.6 \mathrm{bbl}^{-1}\right)$. Reference year is 2015. Top 30 global producers are mapped (see Supplementary Data 1 for full list). Countries are named based on their ISO 3 code. Colour scheme reflects national VWA MC: dark blue for lowest MC, dark red for highest MC. calculated using a well-to-refinery estimation tool, which assesses the emissions due to the production of an additional barrel of crude from a particular oilfield. The profitability is calculated using a microeconomic model, which determines how much money a company is willing to pay to manage an additional barrel of crude located in a particular oilfield (see Methods). The integration of field-specific $\mathrm{Cl}$ and profitability allows us to identify the emissions of fields close to the break-even point (extensive margin of the industry). In other words, we isolate the emissions of those fields where the management choice hangs in the balance between 'how much should I produce?' and 'should I keep producing or cease business operations?'

Our results suggest that an environmental policy designed around non-market informed LCA results could ignore first-order effects. In addition, the structure of the global oil market systematically affects the life-cycle benefits from a decline in oil demand. These results could serve public (for example, the US Department of Energy National Energy Modeling System) and private energy system models to better assess the benefits of technological change within the transportation sector.

\section{Results and discussion Country-level}

Figure 1 presents the global map of national volume-weighted average (VWA) marginal production costs (MC) in 2015. The numbers below the name of each country in the map are the corresponding upstream VWA Cls $\left(\right.$ in $\mathrm{kgCO}_{2} \mathrm{e} \mathrm{bbl}^{-1}$ ). The global average MC estimate-shown by the horizontal dashed line in Fig. $1-$ is $\sim$ US $\$ 5.9$ bbl $^{-1}$ crude oil, with country-level MCs ranging from 2.8 (Iraq (IRQ)) to US $\$ 21.5 \mathrm{bbl}^{-1}$ (Columbia (COL)). Fields with the lowest production costs are mainly conventional resources located in the Middle East and North Africa. There is a wide range of production emissions associated with these regions, with routine flaring as the major driver of high $\mathrm{Cl}$ due to lack of investment/infrastructure for gas handling (see Supplementary Information section 3.3).

Among large producers, Venezuelan, Mexican and Canadian oils are the most expensive and tend to have high production CIs. The US oil industry stands near the global average in terms of GHG emissions and has a high MC ( US\$7.3 $\left.\mathrm{bbl}^{-1}\right)$.

Note that the dynamics of the emissions presented in Fig. 1 can vary over time ${ }^{9,10}$. However, due to the fact that substantial change in production strategies takes time, the relative magnitude of the presented emissions can be expected to hold for a short-term outlook of $<5-10$ years. See Supplementary Information section 3.1 for production economics time-series dissection.

\section{Crude type}

Table1 groups field-level results into summary statistics of a set of global crude classes. Heavy fields (most commonly located in Venezuela) and extra heavy fields (mostly located in Canada) are the least profitable 
Table 1 | 2015 global oilfields characteristics based on crude type

\begin{tabular}{|c|c|c|c|c|c|c|c|c|c|c|}
\hline Crude type & $\begin{array}{l}\text { Share in } \\
\text { global } \\
\text { production } \\
(\%)\end{array}$ & $\begin{array}{l}\text { Total } \\
\text { no. } \\
\text { fields }\end{array}$ & $\begin{array}{l}\mathrm{Cl}^{\mathrm{b}} \\
\left(\mathrm{kgCO}_{2} \mathrm{ebbl}^{-1}\right)\end{array}$ & $\begin{array}{l}\text { Oil price } \\
\left(\text { US } \$ b b l^{-1}\right)\end{array}$ & $\begin{array}{l}M C^{b} \\
\left(U S \$ b b^{-1}\right)\end{array}$ & $\begin{array}{l}\text { SP-PC } \\
\left(U S \$ b^{b} l^{-1}\right)\end{array}$ & $\begin{array}{l}\text { SP-oligopoly }{ }^{b, c} \\
\left(U S \$ b b l^{-1}\right)\end{array}$ & $\begin{array}{l}\text { SP-cartel } \\
\left(U S \$ b^{b}, c\right. \\
\text { (U) }\end{array}$ & $\begin{array}{l}\text { API } \\
\text { gravity } \\
\left({ }^{\circ} \mathrm{API}\right)\end{array}$ & $\begin{array}{l}\text { Flare-to-oil } \\
\text { ratio }^{\mathrm{b}} \\
\left(\mathrm{scfbbl}^{-1}\right)\end{array}$ \\
\hline $\begin{array}{l}\text { Light and } \\
\text { medium }\end{array}$ & $77.5 \%$ & 1,259 & 49.0 & 51.1 & 4.2 & 46.9 & 42.1 & 36.0 & 33.7 & 154.8 \\
\hline Heavy & $8.6 \%$ & 157 & 61.0 & 47.2 & 16.6 & 30.6 & 28.7 & 25.8 & 17.2 & 122.4 \\
\hline $\begin{array}{l}\text { Shale and tight } \\
\text { oil }\end{array}$ & $7.7 \%$ & 314 & 53.4 & 52.2 & 6.8 & 45.5 & 44.9 & 44.6 & 29.8 & 193.7 \\
\hline Oil sands & $2.0 \%$ & 21 & $129.2^{\mathrm{e}}$ & 45.3 & 6.3 & 39.0 & 38.3 & 38.3 & 19.3 & 2.0 \\
\hline Extra heavy & $0.5 \%$ & 9 & 60.3 & 50.1 & 20.2 & 29.9 & 28.9 & 28.9 & 13.7 & 32.3 \\
\hline Other oil $^{d}$ & $3.6 \%$ & 173 & 42.3 & 52.4 & 5.9 & 46.6 & 45.0 & 45.0 & 28.2 & 84.4 \\
\hline Global average & $100.0 \%$ & 1,933 & 51.9 & 50.7 & 5.6 & 45.1 & 41.1 & 36.1 & 31.4 & 148.7 \\
\hline \multicolumn{11}{|c|}{ 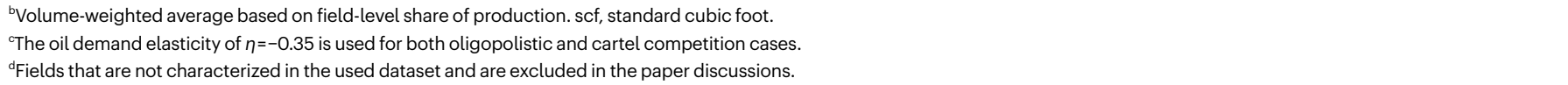 } \\
\hline
\end{tabular}

fields with relatively high MC and low selling price (due to low API gravity). Oil sands have the lowest selling oil price due to low API gravity and high sulfur content. However, their MCs have substantially decreased in recent years ${ }^{11,12}$ making them more competitive vis-à-vis heavy and extra heavy crudes. Contrary to all the other types of crude, oil sands are all located in a single country (Canada). Therefore, they are particularly sensitive to national-specific shocks and transport logistics issues. Shale and tight oil resources are somewhat more competitive, with relatively higher profit margins in all three economic cases, lower emissions, and lighter density crude (higher selling price and lower refining emissions). Conventional light and medium fields are the largest and cheapest to extract crude oil with high selling price, low $\mathrm{MC}$ and relatively low $\mathrm{CI}$.

The average profitability (shadow price (SP)) of different crude types changes accordingly to the assumption on the market structure. In perfect competition (PC), every field is an independent firm, which exerts no market power. In oligopolistic competition (oligopoly), a limited number of firms owns many fields. In cartel competition (cartel), a limited number of firms coordinate their production decisions via a syndicate (for example, the Organization of the Petroleum Exporting Countries (OPEC)-see Methods). In PC, the oilfield SP is the difference between the price at which it sells its output and the MC. The conventional light and medium fields are the most profitable producing units (see SP-PC in Table1). In oligopoly, the volume of production of the firm, which owns the field, affects its SP. In cartel, the volume of production of OPEC affects the SP of the field's member of the union. As a result, in oligopoly and cartel cases, shutting down or reducing production from individually profitable oilfields is rational, since the firm/cartel will sell less output but at a higher price. As a result, in oligopoly and in cartel cases many light and medium fields owned by large international or national oil companies shift to a least profitable position.

Irrespectively of the underlying market structure, heavy fields tend to remain the least profitable formation. Thus, these are the crudes most likely to be displaced by an oil demand reduction. Carbon taxation would also significantly affect their profitability due to their high production $\mathrm{Cl}$. Gas management (that is, routine flaring and methane venting and fugitives) is the major $\mathrm{CI}$ contributor for light and medium, and shale and tight oil crudes. The profitability of these fields is therefore exposed to gas management regulations (for example, production restriction as imposed in eastern Canada $^{13}$ ).

\section{Field-level}

To estimate field-level CI (see Methods), we separate the GHG emissions due to the production of the next barrel from the emissions due to the exploration, and drilling and development. The former identifies the environmental footprint linked to the SP of discovered oil (that is, the one identified in the econometric analysis). The latter-exploration and development emissions-are smaller in most cases and are coupled to the SP of undiscovered oil (not included in this work). Next, the computed SPs of discovered oilfields are sorted from smallest to largest (that is, low to high profitability). As a result, we obtain a merit base curve, which links profitability to production $\mathrm{CI}$ for the three market structures (PC, oligopoly and cartel-see Methods).

Figure 2 combines the upstream cumulative VWA CIs (right axis) and the sorted SPs (left axis), against the percentage of total oil production covered in this work. Analogous to the upstream $\mathrm{CI}^{1}$, the presented wide range of SPs illustrates heterogeneity of production costs due to diverse operational, physical, chemical, and geological properties of different oilfields. Fields in the highest fifth percentile ( US $\left.\$ 53 \mathrm{bbl}^{-1}\right)$ make over $17 \%$ more marginal profit per barrel than the median field $\left(\sim \mathrm{US} \$ 46 \mathrm{bbl}^{-1}\right)$ for all economic cases.

Each local peak along the $\mathrm{CI}$ curve in Fig. 2 indicates an addition of a field with relatively high $\mathrm{Cl}$ and production rate compared to the preceding covered fields. For example, the early sharp peaks by using the cartel model (black curve in Fig. 2) correspond to Venezuelan heavy fields. Large peaks in cumulative Cls at the beginning ( $0-20 \%$ of total production) imply that many less-economic fields with relatively low SPs also emit high GHG emissions (few exceptions are unprofitable depleted conventional fields with low SP and low emissions). These marginal oilfields are consequently more vulnerable to any future carbon taxation/regulation regime and more likely to be displaced by a demand shift.

In all economic cases, the cumulative $\mathrm{CI}$ curve trends downward due to covering fewer emitting fields. This trend continues for the PC case until reaching $51.9 \mathrm{kgCO}_{2} \mathrm{e} \mathrm{bbl}^{-1}$ (at $100 \%$ production coverage), which is the global VWA marginal $\mathrm{CI}$ (see Table1). However, for the other two cases (that is, oligopoly and cartel), including the global oil demand elasticity and market power correction in computing the SP results in less profitability of several low-emitting conventional producers. Thus, for oligopoly and cartel models after few high peaks, the cumulative $\mathrm{Cl}$ curve first trends descending (conventional with low $\mathrm{CI}$ ) and later trends ascending (remaining fields with higher $\mathrm{CI}$ than conventional closer to margin). See Supplementary Information section 3.3 and Supplementary Data 1 for field-level additional data.

\section{Displacement implications}

Many reports estimate near and long-term volume of oil that is going to be displaced and/or stranded by technological developments and/ 
Volume of oil production (MMbbl year ${ }^{-1}$ )

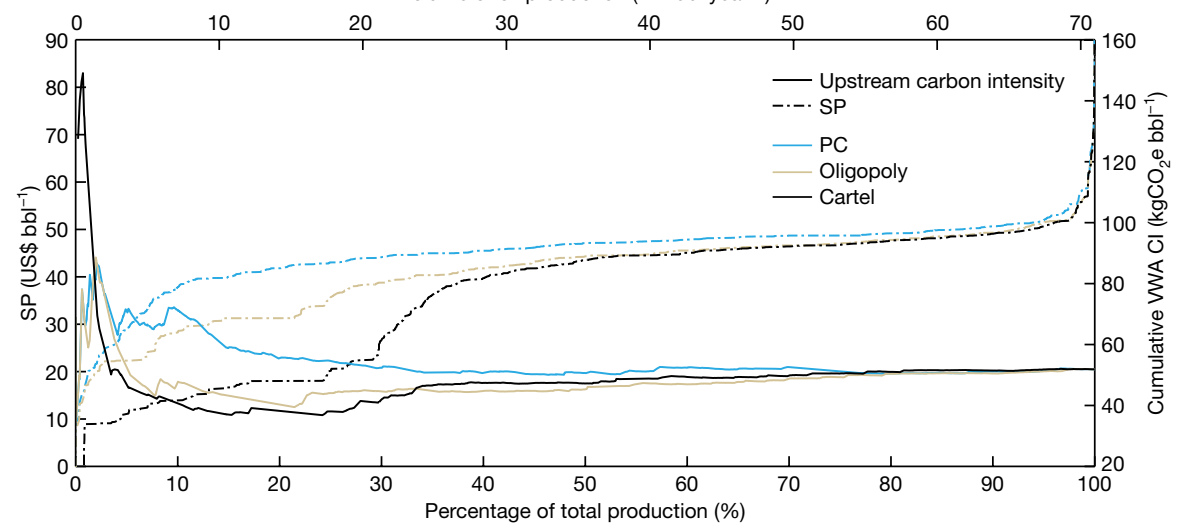

Fig. 2 | Upstream cumulative volume-weighted average CIs (right axis) and sorted SPs (left axis) of global oilfields for PC, oligopoly and cartel economic cases versus the percentage of total oil production in 2015. The oil demand elasticity of $\eta=-0.35$ is used for both oligopoly and cartel

or policy measures ${ }^{14-18}$. These estimates depend on numerous scenario assumptions (for example, growth rate of EVs, global income growth and the way these factors interact) and their conclusions differ markedly.

Instead of selecting any one scenario, we create abstract round number shocks to identify the environmental effect resulting from the displacement of the extensive margin of the oil industry. Such shocks might stem from policies to counter climate change, economic slowdowns, geopolitical conflict, or (as the case in 2020) global diseases like COVID-19. We first consider an oil demand reduction of competition cases. See Supplementary Information section 3.2

(Suppplementary Figs.10 and 11) for results variation based on different oil demand elasticities and further discussions.

$2.5 \%$ relative to the baseline $\left(\sim 1.8\right.$ million barrels per day $\left.\left(\mathrm{MMbbl} \mathrm{d}^{-1}\right)\right)$, which we call small shock scenario. Then, we consider a reduction of $\sim 5 \%\left(-3.6 \mathrm{MMbbl} \mathrm{d}^{-1}\right)$, which we call COVID-19 pandemic scenario due to its resemblance with the contraction in oil demand observed during the 2020 pandemic ${ }^{19,20}$. Finally, we consider a reduction of $\sim 10 \%$ $\left(\sim 7.1 \mathrm{MMbbl} \mathrm{d}^{-1}\right)$, which we call medium shock. The latter could result from a vigorous adoption of alternatives or major macroeconomic downturns like a global financial recession. Note that in medium and large demand reduction scenarios (that is, roughly $>5-10 \%$ ), only the

Table 2 | Characteristics of small and COVID-19 shock scenarios for crude oil demand reduction using different economic models

\begin{tabular}{|c|c|c|c|c|c|c|c|c|c|c|}
\hline \multirow[b]{2}{*}{ Shock scenario $^{d}$} & \multicolumn{3}{|c|}{ Perfect competition (PC) } & \multicolumn{3}{|c|}{ Oligopolistic competition (oligopoly) $^{\mathrm{b}}$} & \multicolumn{3}{|c|}{ Cartel competition (cartel) $^{b}$} & \multirow{2}{*}{$\begin{array}{l}\text { Total (reference) } \\
100 \% \text { reduction }\end{array}$} \\
\hline & $\begin{array}{l}\text { Small } \\
\text { shock, } 2.5 \% \\
\text { reduction }\end{array}$ & $\begin{array}{l}\text { COVID-19 } \\
\text { shock, } 5 \% \\
\text { reduction }\end{array}$ & $\begin{array}{l}\text { Medium } \\
\text { shock, } 10 \% \\
\text { reduction }\end{array}$ & $\begin{array}{l}\text { Small } \\
\text { shock, } 2.5 \% \\
\text { reduction }\end{array}$ & $\begin{array}{l}\text { COVID-19 } \\
\text { shock, } 5 \% \\
\text { reduction }\end{array}$ & $\begin{array}{l}\text { Medium } \\
\text { shock, } 10 \% \\
\text { reduction }\end{array}$ & $\begin{array}{l}\text { Small } \\
\text { shock, } 2.5 \% \\
\text { reduction }\end{array}$ & $\begin{array}{l}\text { COVID-19 } \\
\text { shock, } 5 \% \\
\text { reduction }\end{array}$ & $\begin{array}{l}\text { Medium } \\
\text { shock, } 10 \% \\
\text { reduction }\end{array}$ & \\
\hline $\begin{array}{l}\text { Displaced volume } \\
\left(\mathrm{MMbbld}^{-1}\right)\end{array}$ & 1.8 & 3.6 & 7.1 & 1.8 & 3.6 & 7.1 & 1.8 & 3.6 & 7.1 & 71.0 \\
\hline $\begin{array}{l}\text { Median } \\
\text { production } \\
\left(\text { bbld }^{-1}\right)\end{array}$ & 10,000 & 8027 & 5452 & 12,493 & 21,342 & 19,370 & 38,507 & 68,986 & 50,000 & 7,507 \\
\hline $\begin{array}{l}\text { MC of production } \\
\left(\text { US } \$ b b b l^{-1}\right)\end{array}$ & 26.6 & 21.9 & 18.1 & 26.6 & 15.9 & 14.1 & 11.5 & 10.4 & 7.0 & 5.6 \\
\hline $\mathrm{SP}^{\mathrm{a}}\left(\mathrm{US} \$ \mathrm{bbl}^{-1}\right)$ & 18.6 & 22.5 & 28.3 & 16.9 & 19.7 & 22.3 & 2.3 & 6.5 & 9.9 & $45.1 / 41.1 / 36.1^{c}$ \\
\hline $\mathrm{Cl}^{\mathrm{a}}\left(\mathrm{kgCO}_{2} \mathrm{ebbl}^{-1}\right)$ & 79.7 & 70.6 & 71.2 & 80.3 & 50 & 47.8 & 65 & 45.8 & 40.1 & 51.9 \\
\hline Total no. fields & 37 & 68 & 276 & 33 & 42 & 79 & 16 & 25 & 39 & 1,933 \\
\hline Light and medium & 1 & 2 & 15 & 1 & 52 & 49 & 59 & 75 & 87 & 77.5 \\
\hline
\end{tabular}

(vol\%)

\begin{tabular}{|c|c|c|c|c|c|c|c|c|c|c|}
\hline Oil sands (vol\%) & 0 & 8 & 11 & 0 & 0 & 4 & 0 & 0 & 0 & 2 \\
\hline Heavy (vol\%) & 96 & 85 & 64 & 96 & 47 & 44 & 37 & 23 & 11 & 9 \\
\hline Extra heavy (vol\%) & 0 & 3 & 5 & 0 & 0 & 2 & 0 & 0 & 0 & 1 \\
\hline $\begin{array}{l}\text { Shale and tight oil } \\
\text { (vol\%) }\end{array}$ & 0 & 0 & 2 & 0 & 0 & 0 & 3 & 1 & 1 & 8 \\
\hline $\begin{array}{l}\text { Unconventional } \\
\text { total (vol\%) }\end{array}$ & 96 & 96 & 82 & 96 & 47 & 50 & 40 & 24 & 12 & 19 \\
\hline $\begin{array}{l}\text { Annual upstream } \\
\text { mitigation } \\
\text { potential }\left(\mathrm{MtCO}_{2} \mathrm{e}\right)\end{array}$ & 54 & 92 & 184 & 53 & 69 & 124 & 39 & 61 & 109 & 1,343 \\
\hline
\end{tabular}

${ }^{a}$ Volume-weighted average based on field-level share of production.

${ }^{b} T$ The oil demand elasticity of $\eta=-0.35$ is used for both oligopolistic and cartel competition cases.

'SP-PC, SP-oligopoly, and SP-cartel, respectively.

${ }^{\mathrm{d}}$ The accuracy of estimate is likely to decrease for larger demand reduction shocks (for example, $10 \%$ reduction) of oligopoly and cartel model results. See the corresponding text for further discussion. 


\section{Article}

PC-SP is informative. In the other two cases (that is, oligopoly and cartel), the estimated SP is likely to become uninformative, since the market power correction term would change due to a transformation of the market structure (for example, countries leave/join OPEC, different propensity of countries to respect OPEC quotas, or different outcomes of the game-in-quantities played among oligopolists).

Table 2 characterizes the small, COVID-19, and medium shock scenarios using the different market structures. In PC, the marginal fields are mostly small producers, with median production of $\sim 8,000-$ $10,000 \mathrm{bbl} \mathrm{d}^{-1}$. The oligopoly and cartel cases shift few large conventional producers close to the industry margins (Table 2, and bar widths in Supplementary Figs. 12-14). The shift occurs for the same reasons explained above. Namely, oligopolists and members of the cartel adjust production from profitable fields to maximize their total profit.

In all three economic models, the VWA MC of the marginal fields is much higher (25-375\%) than the global average MC of $\sim$ US $\$ 5.6 \mathrm{bbl}^{-1}$. Shifting low carbon intensive light and medium conventional fields towards the margin lowers the average $\mathrm{CI}$ of the displaced oil, but several heavy fields stay at the margin. We conclude that oil demand shocks result in nonlinear carbon emissions reduction. In all three economic cases, the $\mathrm{Cl}$ of the crudes displaced by the small shock is $-25-54 \%$ larger than the global average of $51.9 \mathrm{kgCO}_{2} \mathrm{e} \mathrm{bbl}^{-1}$. The $\mathrm{CI}$ of the displaced crudes by COVID-19 shock is $\sim 35 \%$ larger than the global average for $\mathrm{PC}$, but is close to the global average $\mathrm{CI}$ using oligopolistic and cartel competition. The PC model still provides accurate estimates for $10 \%$ reduction shock where the $\mathrm{Cl}$ of the displaced crudes is $\sim 37 \%$ larger than the global average. However, the oligopoly and cartel models might not capture the market behaviour for such a large shock. The average CIs for these two economic cases due to $10 \%$ demand reduction are lower than global average with large volume share of light and medium crudes being displaced due to market power considerations.

The demand reduction magnitude affects the average $\mathrm{Cl}$ of displaced crudes. Heavy oilfields with high $\mathrm{Cl}$ (mostly located in Venezuela) have consistent contribution in all demand reduction scenarios and across all economic models. The total share of unconventional crudes (by volume) generally decreases by including market power corrections in the economic model, as it becomes more viable for large national oil companies to exert market power by reducing production from productive conventional fields. Our results show that given the proposed three economic cases, the small, COVID-19 and $10 \%$ reduction shocks in the global oil demand would result in the elimination of 39-54, 61-92 and 109-184 $\mathrm{MtCO}_{2}$ e per year of upstream emissions, respectively. Supplementary Figure 15 shows a full range of annual carbon mitigation potential versus the amount of oil displaced using the three economic models. Larger reductions of GHG emissions associated with refining of oil and the final combustion of corresponding products would also occur, but are not included in these calculations. See Supplementary Information section 4.2 and Supplementary Table 8 for well-to-wheel mitigation potential estimate ranges and further discussions on demand sector GHG emissions.

In this work, we only included the production economics and identified the extensive margin of the oil industry. However, various other dynamic forces such as production agreements, region-specific fiscal regimes, regulations (for example, fuel standard policies), geopolitics (for example, sanctions, trade wars), technical advances and incidental events could move a particular oilfield toward or away from the margin. Further analysis of these factors is beyond the scope of this work, but could be pursued in future research (see Supplementary Information section 5).

\section{Online content}

Any methods, additional references, Nature Research reporting summaries, source data, extended data, supplementary information, acknowledgements, peer review information; details of author contributions and competing interests; and statements of data and code availability are available at https://doi.org/10.1038/s41586-021-03932-2.

1. Masnadi, M. S. et al. Global carbon intensity of crude oil production. Science $\mathbf{3 6 1}$, 851-853 (2018).

2. Wallington, T. J. et al. When comparing alternative fuel-vehicle systems, life cycle assessment studies should consider trends in oil production. J. Ind. Ecol. 21, 244-248 (2017).

3. Mintz-Woo, K., Dennig, F., Liu, H. \& Schinko, T. Carbon pricing and COVID-19. Clim. Policy https://doi.org/10.1080/14693062.2020.1831432 (2020).

4. Barbosa, F., Bresciani, G., Graham, P., Nyquist, S. \& Yanosek, K. Oil and Gas After COVID-19: The Day of Reckoning or a New Age of Opportunity (McKinsey Company, 2020).

5. Jing, L. et al. Carbon intensity of global crude oil refining and mitigation potential. Nat Clim. Change 10, 526-532 (2020).

6. Earles, J. M. \& Halog, A. Consequential life cycle assessment: a review. Int. J. Life Cycle Assess. 16, 445-453 (2011).

7. Plevin, R. J., Delucchi, M. A. \& Creutzig, F. Using attributional life cycle assessment to estimate climate-change mitigation benefits misleads policy makers. J. Ind. Ecol. 18, 73-83 (2014).

8. Yang, Y. \& Heijungs, R. On the use of different models for consequential life cycle assessment. Int. J. Life Cycle Assess. 23, 751-758 (2018).

9. Masnadi, M. S. \& Brandt, A. R. Climate impacts of oil extraction increase significantly with oilfield age. Nat. Clim. Change 7, 551-556 (2017).

10. Masnadi, M. S. \& Brandt, A. R. Energetic productivity dynamics of global super-giant oilfields. Energy Environ. Sci. 10, 1493-1504 (2017).

11. Costs of Canadian oil sands projects fell dramatically in recent years; but pipeline constraints and other factors will moderate. Bloomberg https://www.bloomberg.com/ press-releases/2019-05- 01/costs-of-canadian-oil-sands-projects-fell-dramatically-inrecent-years- but-pipeline-constraints- and-other-factors-will-moderate (1 May 2019).

12. Canadian oil sands dialogue. HIS Markit https://ihsmarkit.com/products/ energy-industry-oil-sands-dialogue.html?ocid=cera- osd:energy:print:0001 (accessed: 30 June 2020).

13. Newfoundland and Labrador Offshore Area Gas Flaring Reduction Implementation Plan (The Canada-Newfoundland and Labrador Offshore Petroleum Board, 2017); https://www. cnlopb.ca/legislation/regulations/

14. Eberhart, D. The oil sector will survive the arrival of the electric car just fine. Forbes https://www.forbes.com/sites/daneberhart/2018/03/22/the- oil-sector-will-survive-thearrival-of-the- electric-car-just-fine/\#273b75267155 (22 May 2018).

15. Kah, M. Electric Vehicle Penetration and Its Impact On Global Oil Demand: A Survey of 2019 Forecast Trends (Columbia University Center Global Energy Policy, 2019).

16. Sharma, G. Are electric vehicles really about to plateau oil demand? Forbes https://www. forbes.com/sites/gauravsharma/2019/11/25/are- electric-vehicles-really-about-to-plateauoil-demand/\#7f0853083b13 (25 November 2019).

17. Electric Vehicle Outlook 2020 (BloombergNEF, 2020); https://about.bnef.com/ electric-vehicle-outlook/

18. Global EV Outlook 2019 (IEA, 2019); https://www.iea.org/reports/global-ev-outlook2019\#executive-summary

19. Short-Term Energy Outlook (EIA, 2020); https://www.eia.gov/outlooks/steo/report/global_ oil.php

20. Global Energy Review 2020 (IEA, 2020); https://www.iea.org/reports/ global-energy-review-2020/

21. El-Houjeiri, H. M., Masnadi, M. S., Vafi, K., Duffy, J. \& Brandt, A. R. Oil Production Greenhouse Gas Emissions Estimator OPGEE v2.0a: User Guide \& Technical Documentation (California Environmental Protection Agency, 2017).

Publisher's note Springer Nature remains neutral with regard to jurisdictional claims in published maps and institutional affiliations.

(C) The Author(s), under exclusive licence to Springer Nature Limited 2021 


\section{Methods}

\section{Research scope}

This work covers upstream emissions (including production and transport of crude oil to refinery gate) and costs. Due to lack of access to refinery cost data, we cannot generate a fully market-informed (consequential) well-to-wheel emissions analysis that goes all the way to refined fuels. Nevertheless, we provide a discussion on how upstream displacement could affect the emissions of the demand side (see Supplementary Information section 4.2).

\section{Carbon intensity model}

The field-level $\mathrm{CI}$ is estimated using the Oil Production Greenhouse Gas Emissions Estimator (OPGEE version 2.0) 21-23 . OPGEE is an open-source, peer-reviewed ${ }^{9,10,21,24-31}$, bottom-up, engineering-based model. The OPGEE system boundary is 'well-to-refinery' (WTR, that is, exploration, drilling and development, production and extraction, surface processing, maintenance, waste disposal, and crude transport to the refinery). Reported emissions are measured in $\mathrm{gCO}_{2}$ e emitted per $1 \mathrm{MJ}$ lower heating value (LHV) of crude petroleum delivered to the refinery entrance gate. All GHGs are converted to $\mathrm{gCO}_{2} \mathrm{e}$ using AR5 GWP100 conversion factors (without carbon feedback) ${ }^{32}$. See the OPGEE user guide $^{21}$ for more details of each process stage.

OPGEE estimates $\mathrm{Cl}$ using up to 50 parameters as input data for each modelled oilfield. If input data are not available for some parameters (common), OPGEE supplies defaults based on statistical analysis of petroleum engineering literature and commercial data sources (for example Oil \& GasJournal (O\&GJ) ${ }^{33}$ ) enabling the software to estimate a field's CI without complete data ${ }^{21,33}$.

In this work, field exploration, and drilling and development emissions are excluded from CIs reported in prior work ${ }^{1}$ to estimate $\mathrm{GHG}$ emissions associated with production of the next barrel of crude oil (that is, marginal upstream CIs). These two sectors hold a very low share of the total upstream GHG emissions (see supplementary Fig. S20 of ref. ${ }^{1}$ ).

\section{Global oilfields}

In the previous work ${ }^{1}$, CIs were estimated for 8,966 global active oilfields (so-called child fields) supplying 78.9 million barrels per day ( $\mathrm{MMbbl} \mathrm{d}^{-1}$ ), and capturing $\sim 98 \%$ of 2015 global crude oil and condensate production ${ }^{34}$. A combination of government reported data (Norway $^{35,36}$, Canada ${ }^{37-40}$, Denmark ${ }^{41}$, UK $^{42}$, Nigeria ${ }^{43}$, and US California $^{44}$, US Alaska ${ }^{45}$ and US shale oils ${ }^{46}$ ), public literature (total of nearly 800 sources) and proprietary/commercial data sources (O\&GJ 2015 survey $^{33}$ and Wood Mackenzie (WM) oilfield datasets ${ }^{47}$ ) were used as input data ${ }^{1}$. Government and public literature data were collected and used for 1,009 global fields, accounting for about $64.3 \%$ of global crude oil production. Commercial data are utilized for the remainder (mostly small fields). We select 2015 as the reference year due to lags in some data sources. See our previous study supplementary materials document ${ }^{1}$ for further details.

\section{Economic model}

We frame our economic model as a profit-maximization problem. We study three different cases described here heuristically with mathematical details presented in the Supplementary Information. In the perfect competition (PC) case, every field is an independent firm which exerts no market power. In this context, the field management solves the profit-maximization problem taking the oil price as given. In the oligopolistic competition (oligopoly) case, a limited number of firms owns many fields. In this context, the field management solves the profit-maximization problem knowing that the quantity of oil produced by the firm who owns the field as well as its competitors influences the oil price. In the cartel competition (cartel) case, a limited number of firms coordinate their production decisions via a syndicate. In this context, the field management solves the profit-maximization problem knowing that the quantity of oil produced by the members of the syndicate influences the oil price. Said differently, in the oligopoly case a small number of oligopolistic competitors play a game-in-quantities. In the cartel case, a few firms work together to coordinate their production decisions around a union. In our model, the members of the cartel are the national oil companies associated with OPEC. Due to the complexities in modelling the realities of cartel dynamics, our cartel case assumes that the cartel operates in unison. The effect of a cartel with imperfect coordination would fall somewhere between individual company market power (oligopoly case) and the perfect cartel (cartel case).

In the PC case, field profits are the difference between field revenues and field costs, which we divide into two macro-classes: (1) costs to extract the oil (extraction costs) and (2) costs to discover new oil (exploration costs),

$$
\begin{aligned}
\text { Profits }= & (\text { oil price } \times \text { volumes of oil extracted }) \\
& - \text { extraction costs }- \text { exploration costs. }
\end{aligned}
$$

In the oligopoly and cartel cases, the field profits are the same. However, in the oligopoly case the management takes into consideration the effect of the volumes of oil produced by the firm who owns the field on the oil price, while in the cartel case the management takes into consideration the effect of the volumes of oil produce by the cartel on the oil price.

In all three cases, the decision choices are: what volume of oil to extract and how much money to spend in exploration ${ }^{48,49}$. While making these decisions the management faces two physical constraints. First, the quantity of reserves available at time $t$ equals the reserves at time $t-1$ minus the volumes of oil extracted at time $t$ plus the quantity of oil discovered at time $t$. Second, the cumulative discoveries at time $t$ equals the cumulative discoveries until time $t-1$ plus the discoveries at time $t$.

The first-order condition of the optimization problem with respect to the volumes of oil extracted identifies how much money a producer is willing to spend to manage one extra barrel of oil. This value is called shadow price (of discovered oil),

$$
\begin{aligned}
\text { Shadow price }= & \text { oil price }- \text { marginal extraction cost } \\
& + \text { market power correction term } .
\end{aligned}
$$

The shadow price (SP) equals the difference between the oil price and the marginal extraction cost $(\mathrm{MC})^{50}$ (that is, the cost of extracting the next barrel; this quantity is obtained by taking the first-order derivative of the extraction costs with respect to volumes of oil extracted) readjusted by a market power correction term.

If every field is an independent firm with no capacity to influence price (that is, $\mathrm{PC}$ ), the market power correction term shrinks to zero and the SP becomes the difference between the oil price and the MC. For example, if a field sells its output at US $\$ 50 \mathrm{bbl}^{-1}$ and its MC is US $\$ 40 \mathrm{bbl}^{-1}$, the owner of the field is willing to spend (up to) US $\$ 10$ to manage one more barrel located in that particular deposit. In the case of oligopolistic competition/perfect collusion behaviour, the SP takes into account the capacity of the firm/cartel to influence the global (average) oil price rescaled by the propensity of consumers to decrease the quantity of oil consumed due to an increase in oil price. Section 1 of the Supplementary Information provides the mathematical details of the economic framework linking the concept of SP to standard oil economics.

As the SP of a field approaches zero, the management problem shifts from 'how much should I produce?' (intensive margin choice) to 'should I produce or not?' (extensive margin choice). In other words, the fields with a SP close to zero identify the extensive margin of the oil industry. The emissions of this portion of the industry are the most sensitive to a drop in oil price caused by a reduction in the transportation fuel demand. 
Note that estimating field-level gross profit was the main aim of this work, not the net profit. The gross profit is a better representative of fields' geological and physical characteristics and production practices, whereas the net profit includes additional fiscal regimes (that is, royalties, severance taxes, income taxes, production sharing and so on), which are complex, country/region-specific and subject to change. Incorporating these fiscal terms is out of the capacity and the scope of the presented work.

\section{Econometric analysis}

All three variables making up SP are unobserved. To estimate them, we face three econometric problems: (1) the non-stationary nature of oil prices, (2) the endogenous link between costs, quantities and reserves, and (3) the uncertainty about the magnitude of the oil demand elasticity.

We do not know the price at which a field sells its output because we do not have access to commercial agreements between oil producers and oil refiners. However, we know the prices of publicly traded oil classes. More precisely, we know the landed costs of imported crudes in the United States from 1979 to $2018^{51}$, as well as some key physical and chemical characteristics of every traded class ${ }^{52}$ (see Supplementary Fig. 1 and Supplementary Table 1. In the same way, we know the average price at which US refineries buy imported crudes ${ }^{53}$ and the average physical and chemical characteristics of crudes imported in the United States $^{54}$. The physical and chemical characteristics most important to refineries are the crude density (measured as API gravity) and the sulfur content (measured as wt $\%$ sulfur).

We regress the difference between the price of a particular oil class and the average price at which refineries buy imported crudes on the differences between the API gravity of the oil class and the average API gravity of imported crudes as well as on the difference between the sulfur content of the oil class and the average sulfur content of imported crudes $^{55-57}$. In doing so, we solve the non-stationarity problem while assuming that the difference between the price of a particular oil class and the average one is a linear function of the oil's characteristics. We allow these linear deviations to be time-specific to adjust for changing in demand of transportation fuels as well as for technological change within the refinery sector. For example, in 2015 the average oil price was US $\$ 50.39 \mathrm{bbl}^{-1}$, its API gravity 31.46 , and its sulfur content $1.40 \%$. In 2015 increasing the API gravity by one degree increased the value of a crude stream by US $\$ 0.13 \mathrm{bbl}^{-1}$, while increasing sulfur content by $1 \%$ lowered the value of a crude stream by US $\$ 2.86 \mathrm{bbl}^{-1}$. In 2016 , these two quantities were +US $\$ 0.03 \mathrm{bbl}^{-1}$ and $-\mathrm{US} \$ 0.85 \mathrm{bbl}^{-1}$. This change could be due to (1) a modification in the composition of the demand for transportation fuels (for example, more demand for gasoline, less demand for diesel), (2) a change in the technologies employed by US refineries, and (3) a combination of (1) and (2). Our econometric model is flexible enough to take into account all three possibilities (see Supplementary Information section 2.1).

We can use the two structural coefficients, which weight the impact of API gravity and sulfur content, to estimate field-level selling prices (see Supplementary Information section 2.1, equation 8). Using the API gravity and sulfur content reported in the $2018 \mathrm{WM}$ dataset ${ }^{47}$, we estimate the selling price of 1,933 'parent project' fields over the decade 20092018 , thereby obtaining $1,933 \times 10=19,330$ simulated selling prices (see Supplementary Information section 2.1 for a detailed discussion on the results). See Supplementary Figs. 2 and 3 for a cross-sectional snapshot.

Next, we estimate the MC. An accurate measurement of MC is complicated because it is difficult to determine which factors of production are fixed and which are variable. However, the use of detailed accounting data, combined with standard econometric techniques, allows us to have a good first-order approximation of the MC of different types of fields. We use the WM dataset to obtain yearly cost data for the same 1,933 fields over the time interval 2009-2018. Then, we obtain the extraction costs summing the operational expenditures (OPEX), which include consumable inputs, labour, maintenance, repairs, accounting costs, license fees, office expenses, utilities and insurance. We also include capital expenditures not linked to exploration activities (non-exploration CAPEX, which include installation, acquisition, upgrading and restoring of the physical assets used to extract the oil).

After computing the extraction costs, we regress them against the volumes of oil extracted while controlling for the depletion level of the field, the geological characteristics of the field, and technological trends in the broader oil industry ${ }^{58}$. We estimate the structural coefficients of the cost function re-expressing the regression in first differences. The combination of the longitudinal structure of the dataset with the first-difference estimation method allows us to attenuate (or in the best case scenario to solve) eventual endogeneity problems ${ }^{59}$. The first-order derivative of the fit returns the estimated MC. Section 2.3 of Supplementary Information provides all the econometric details.

Finally, for two of the three cases analysed, we compute the market power correction term. Its expression is the same in both cases. Namely, the capacity of the firm/cartel to influence the average oil price rescaled by the capacity of consumers to lower their demand for oil-derived products when their prices increase. Said differently, the market power correction term adjusts the SP of every field by capturing the effect of a unit increase in the production of a specific field on the equilibrium oil price and, in turn, on the firm's profits. Higher market power-corresponding to larger firm size-implies, ceteris paribus, a lower shadow price, because the effect of a fall in price due to the production of an extra unit of crude on the firm total revenues is proportional to the total production. For instance, if the production of an extra barrel causes the oil price to fall by 0.01 cents, then the firm must trade-off the profits generated by selling that extra barrel and a loss of 0.01 cents per barrel times the total number of barrels produced by the firm. Thus, accounting for market power makes the marginal unit produced by each firm/ cartel less valuable, resulting in lower SPs. This effect is increasing in the firm/cartel size. Since the magnitude of the oil demand elasticity is object of econometric debate ${ }^{60}$, we validate our results using different point estimates within the interval -0.20 up to -0.35 .

\section{Data matching and coverage}

The previous work on the Cl of global oilfields ${ }^{1}$ is provided at a child field level. Child fields are individual discoveries that are part of a parent project. Parent fields are combinations of geologic deposits collected for the purposes of a combined valuation. The linkage with the economic data, available only at parent level, requires us to match the child field $\mathrm{CIs}^{1}$ to parent fields. The majority of the child non-technical oilfields from WM datasets ${ }^{47}$ (accessed 2018)-whose corresponding parent fields are available-directly matched with the OPGEE global dataset. We paired the remaining with smart string search and string distance matching using $R$ as well as manual matching for the countries with poor total production coverage. Finally, we conduct an additional treatment on two important global producers (Canada and United States) based on the available data (see Supplementary Information section 2.2).

After the matching process is completed, we examine the representativeness of our techno-economic dataset. In total, we matched 1,933 parent fields located in 77 countries. Their combined production is $\sim 71 \mathrm{MMbbl} \mathrm{d}^{-1}$ and it captures $\sim 90 \%$ of the 2015 global crude oil and condensate production ${ }^{34}$. Supplementary Table 5 returns the coverage summary of the top 20 largest global producers, and Supplementary Fig. 4 zooms in on the geographic location and the $\mathrm{Cl}$ of the mapped fields.

\section{Data availability}

The field-level environmental and economic dataset generated during the current study are provided as a separate Excel file at https://doi. org/10.6084/m9.figshare.15029565. The carbon intensity data are taken from https://doi.org/10.1126/science.aar6859. The core economic datasets 
used during the current study (that is, the Wood Mackenzie dataset) are not publicly available due to them being proprietary/commercial datasets.

\section{Code availability}

The custom software or code is not central to the paper or required to support the main results being reported in the manuscript. Thus, all custom codes are available upon request.

22. LCFS Crude Oil Lifecycle Assessment (California Air Resources Board, 2017); https://www. arb.ca.gov/fuels/lcfs/crude-oil/crude-oil.htm

23. OPGEE: The Oil Production Greenhouse gas Emissions Estimator (Environmental Assessment \& Optimization Group, 2017); https://eao.stanford.edu/research-areas/opgee

24. Vafi, K. \& Brandt, A. GHGfrack: an open-source model for estimating greenhouse gas emissions from combustion of fuel during drilling and hydraulic fracturing. Environ. Sci. Technol. 50, 7913-7920 (2016).

25. El-Houjeiri, H. M., Brandt, A. R. \& Duffy, J. E. Open-source LCA tool for estimating greenhouse gas emissions from crude oil production using field characteristics. Environ. Sci. 47, 5998-6006 (2013).

26. Masnadi, M. S. et al. Well-to-refinery emissions and net-energy analysis of China's crude oil supply. Nat. Energy 3, 220-226 (2018).

27. Brandt, A. R., Masnadi, M. S., Englander, J. G., Koomey, J. \& Gordon, D. Climate-wise choices in a world of oil abundance. Environ. Res. Lett. 13, 044027 (2018).

28. Brandt, A. R., Sun, Y., Bharadwaj, S., Livingston, D. \& Tan, E. Energy return on investment (EROI) for forty global oilfields using a detailed engineering-based model of oil production. PLOS ONE 10, e0144141 (2015).

29. Brandt, A. R., Englander, J. \& Bharadwaj, S. The energy efficiency of oil sands extraction: energy return ratios from 1970 to 2010. Energy 55, 693-702 (2013).

30. Brandt, A. R., Sun, Y. \& Vafi, K. Uncertainty in regional-average petroleum GHG intensities: countering information gaps with targeted data gathering. Environ. Sci. Technol. 49 679-686 (2014).

31. Tripathi, V. \& Brandt, A. Estimating decades-long trends in petroleum field energy return on investment (EROI) with an engineering-based model. PLOS ONE 12, e0171083 (2017).

32. Myhre, G. et al. Anthropogenic and natural radiative forcing. In Climate Change 2013: The Physical Science Basis. Contribution of Working Group I to the Fifth Assessment Report of the Intergovernmental Panel on Climate Change (eds. Stocker, T. F. et al.) (Cambridge Univ. Press, 2013).

33. Worldwide Oil Field Production Survey 2015 (PenWell, 2015).

34. Total Petroleum and Other Liquids Production - 2016 (EIA, 2017); https://go.nature. com/3jink3

35. Norway Petroleum Directorate (NPD, 2017); https://factpages.npd.no/en/field/PageView

36. Feltspesifikke Utslippsrapporter 2015 (Norsk Olje \& Gass, 2015); https://www. norskoljeoggass.no/page-not-found/migrering/feltspesifikke-utslippsrapporter-2015/

37. Statistical Reports (ST) (Alberta Energy Regulator, 2015); https://portal.aer.ca/ providing-information/data-and-reports/statistical-reports.html

38. Statistical information (C-NLOPB, 2021); https://www.cnlopb.ca/information/ statistics/\#rm

39. Estimated Production of Canadian Crude Oil and Equivalent (National Energy Board, 2017); https://www.cer-rec.gc.ca/en/data-analysis/energy-commodities/crude-oilpetroleum-products/statistics/estimated-production-canadian-crude-oil-equivalent.html

40. BASIN database. Natural Resources Canada http://basin.gdr.nrcan.gc.ca/index_e.php (accessed: 15 November 2017)

41. 2015 Production (Danish Energy Agency, 2016); https://ens.dk/en/our-responsibilities/ oil-gas

42. Oil and Gas: Field Data (UK Government, 2017); https://www.gov.uk/guidance/ oil-and-gas-uk-field-data

43. Annual Statistical: 2015 Statistical Bulletin (Nigerian National Petroleum Corporation, 2015); https://nnpcgroup.com/Public-Relations/Oil-and-Gas-Statistics/Pages/ Annual-Statistics-Bulletin.aspx
44. 2015 Report of California Oil and Gas Production Statistics (State of California Department of Conservation, the Division of Oil, Gas, \& Geothermal Resources, 2015); ftp://ftp.consrv. ca.gov/pub/oil/annual_reports/2015/PR03_2015.pdf

45. Alaska Oil and Gas Conservation Commission (Alaska Department of Administration, 2017); https://www.commerce.alaska.gov/web/aogcc/Data.aspx

46. Drilling Productivity Report (EIA, 2021); https://www.eia.gov/petroleum/drilling/

47. Upstream data tool. Wood Mackenzie https://www.woodmac.com/research/products/ upstream/upstream- data-tool/ (2018)

48. Devarajan, S. \& Fisher, A. C. Exploration and scarcity. J. Polit. Econ. 90, 1279-1290 (1982).

49. Pindyck, R. S. The optimal exploration and production of nonrenewable resources. J. Polit. Econ. 86, 841-861 (1978).

50. Pesaran, M. H. An econometric analysis of exploration and extraction of oil in the UK Continental Shelf. Econ. J. 100, 367-390 (1990).

51. Landed Costs of Imported Crude for Selected Crude Streams (EIA, 2020); https://www. eia.gov/dnav/pet/pet_move_land2_k_a.htm

52. The Crude Oils And Their Key Characteristics (PSA, 2020); https://www.psa-bv.nl/files/ CrudeOils.pdf

53. Total Energy Data (EIA, 2021); https://www.eia.gov/totalenergy/data/browser/csv. php?tbl=T09.01

54. Crude Oil Input Qualities (EIA, 2021); https://www.eia.gov/dnav/pet/pet_pnp_crq_dcu_ nus_a.htm

55. Kilian, L. \& Murphy, D. P. Why agnostic sign restrictions are not enough: understanding the dynamics of oil market VAR models. J. Eur. Econ. Assoc. 10, 1166-1188 (2012).

56. Fattouh, B. The dynamics of crude oil price differentials. Energy Econ. 32, 334-342 (2010).

57. Bacon, R. \& Tordo, S. Crude Oil Price Differentials and Differences in Oil Qualities: A Statistical Analysis Technical Paper No. 81 (ESMAP, 2005); https://openknowledge. worldbank.org/handle/10986/18006

58. Henningsen, A. Introduction to Econometric Production Analysis with $R$ (Leanpub, 2014).

59. Kawaguchi, K. ECON5630 Topics in empirical industrial organization. GitHub https:// kohei-kawaguchi.github.io/EmpiricallO/ (last accessed 31 January 2021).

60. Kilian, L. Understanding the estimation of oil demand and oil supply elasticities (2020).

61. Sleep, S. et al. Improving robustness of LCA results through stakeholder engagement: a case study of emerging oil sands technologies. J. Clean. Prod. 281, 125277 (2021).

Acknowledgements The authors want to thank J.-C. Monfort from Aramco Americas for help creating the global map display.

Author contributions M.S.M., G.B. and A.R.B. developed the carbon model and linked the economic and environmental data. G.B. A.M. V.D., H.M.E. M.S.M. and P.J. developed the economic model. M.S.M., G.B., A.R.B., J.E.A., T.J.W., R.D.K. and H.M.E. contributed on the broader implications of the study. M.S.M., G.B., A.M. and H.M.E. contributed to improve the manuscript displays. M.S.M. organized and processed the material and wrote the paper.

Competing interests Work at Stanford University on this project was primarily funded by Ford Motor Company through a gift to Stanford University. Other funding at Stanford University was provided by Aramco Americas. Some co-authors are employed by industry. Every effort was made to maintain independence and accuracy in this work. Industry collaborations were vital to obtaining and accurately analysing the detailed oilfield financial data used in this study.

Additional information

Supplementary information The online version contains supplementary material available at https://doi.org/10.1038/s41586-021-03932-2.

Correspondence and requests for materials should be addressed to Mohammad S. Masnadi or Adam R. Brandt.

Peer review information Nature thanks Kausik Chaudhuri, Sujit Das and the other, anonymous, reviewer(s) for their contribution to the peer review of this work. Peer reviewer reports are avilable.

Reprints and permissions information is available at http://www.nature.com/reprints. 